UC-910 and UC-906

Issued: November 1997

An Experimental Investigation of an

Air Cooling Scheme for Removing

Environmentally Imposed Heat Loads

from the Multiplicity and Vertex Detector's

Main Enclosure

R. Cunningham

J. D. Bernardin

J. Simon-Gillo
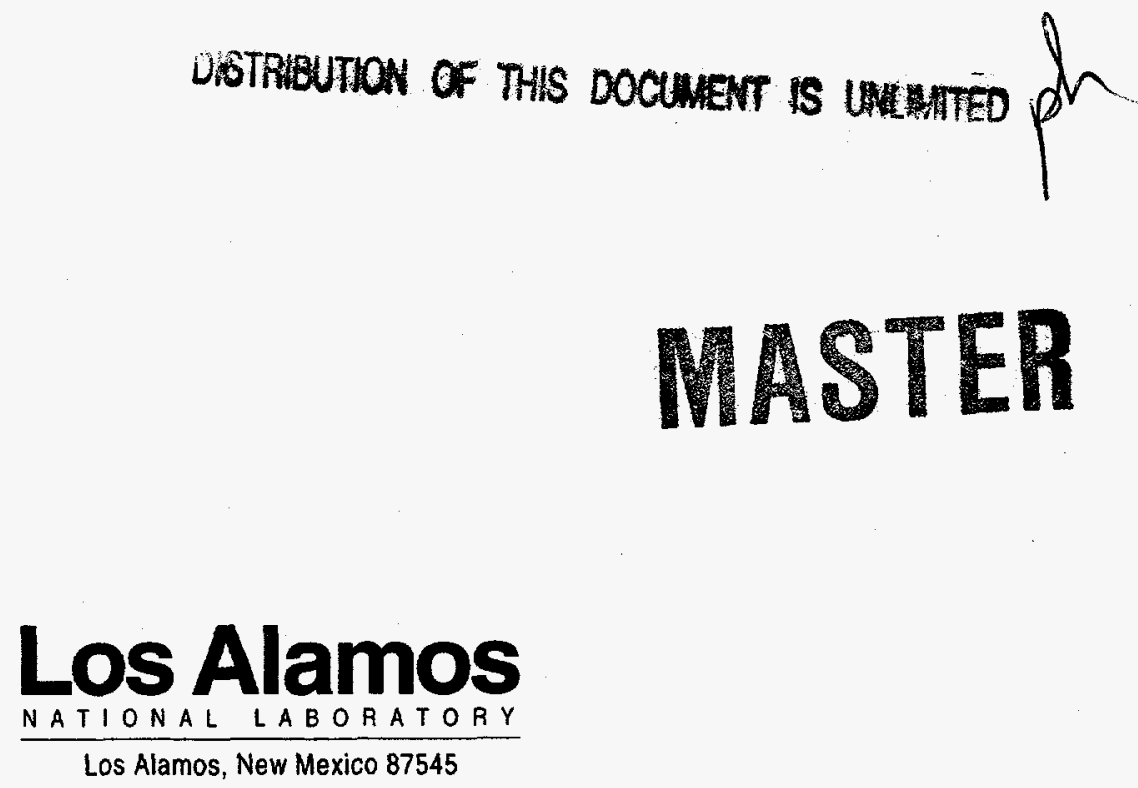


\section{DISCLAIMER}

This report was prepared as an account of work sponsored by an agency of the United States Government. Neither the United States Government nor any agency thereof, nor any of their employees, make any warranty, express or implied, or assumes any legal liabiity or responsibility for the accuracy, completeness, or usefulness of any information, apparatus, product, or process disclosed, or represents that its use would not infringe privately owned rights. Reference herein to any specific commercial product, process, or service by trade name, trademark, manufacturer, or otherwise does not necessarily constitute or imply its endorsement, recommendation, or favoring by the United States Government or any agency thereof. The views and opinions of authors expressed herein do not necessar. ily state or reflect those of the United States Government or any agency thereof. 


\section{DISCLAIMER}

Portions of this document may be illegible electronic image products. Images are produced from the best available original document. 


\title{
An Experimental Investigation of an Air Cooling Scheme for Removing Environmentally Imposed Heat Loads from the Multiplicity and Vertex Detector's Main Enclosure
}

by

\author{
R. Cunningham, J.D. Bernardin, and J. Simon-Gillo
}

\begin{abstract}
This report presents a summary of an experimental investigation of a closed loop air cooling system designed to control the temperature and humidity in the main enclosure of the multiplicity and vertex detector (MVD). Measurements of the cooling air flow rate, the humidity levels inside and outside of the MVD, and the cooling air temperatures were used to assess the performance of the system and to characterize the system limitations and potential assembly problems. The results of the study indicate that several design changes are needed in the final design to meet the temperature and humidity operating requirements. A thorough set of design change recommendations that satisfy these operating criteria completes this report.
\end{abstract}

\section{NOMENCLATURE}

Symbol
$c_{p}$
$\gamma$
$P$
$Q$
$q$
$\rho$
$T$

\section{Subscript}

$B N L$

env

$f$

$i$

$L A N L$

$M V D$

$o$
Description

Specific heat $(\mathrm{J} / \mathrm{kg} \mathrm{K})$

specific humidity ( $\mathrm{kg} \mathrm{H}_{2} \mathrm{O} / \mathrm{kd}$ Air)

pressure

Volumetric flow rate $\left(\mathrm{m}^{3} / \mathrm{s}\right)$

Power dissipation (W)

Density $\left(\mathrm{kg} / \mathrm{m}^{3}\right)$

Temperature $\left({ }^{\circ} \mathrm{C}\right)$

Description

Brookhaven National Laboratory

environment

liquid

inlet

Los Alamos National Laboratory

property of the MVD

outlet 


\section{INTRODUCTION}

The multiplicity and vertex detector (MVD) is being developed to determine and characterize the collision location of heavy ions in the PHENIX experiment at the Relativistic Heavy Ion Collider at Brookhaven National Laboratory. Detailed information concerning all aspects of the MVD has been published [1,2], so only a brief introduction to the enclosure components that relate to the current study will be presented here.

The MVD, shown in Figure 1, is made up of two symmetrical enclosures which open up in a "clam-shell" fashion to allow for installation around the beam pipe in which the ion collisions occur. Each enclosure houses twelve "C-shaped" cages which each contain several silicon strip detectors used to detect charged particles emitted during heavy ion collisions. The "C-shaped" cages are made of Rohacell, a very strong and low density foam. Because Rohacell is a very hygroscopic material, the dimensions of the Rohacell cages are dependent upon the humidity level of the air inside the MVD enclosure $[3,4]$. To obtain accurate placement of the silicon detectors, the humidity level of the air within the MVD enclosure must be controlled. Temperature control is also necessary, due to the dependence of the silicon detectors' signal-to-noise ratio on temperature. Should the detectors suffer radiation damage, they will require lower operating temperatures to continue to function in a satisfactory manner. In addition, a certain amount of waste heat will be transmitted to the MVD enclosure by the environment. A forced convection air cooling system, described in this paper, will be used to remove this waste heat and control atmospheric conditions inside the MVD.

A study by van Heck [4] showed that the vertex finding efficiency of the MVD was highly dependent on the known location of the silicon strip detectors. van Heck used the humidity dependent Rohacell deformation characteristics reported by Bosze et al. [3] 


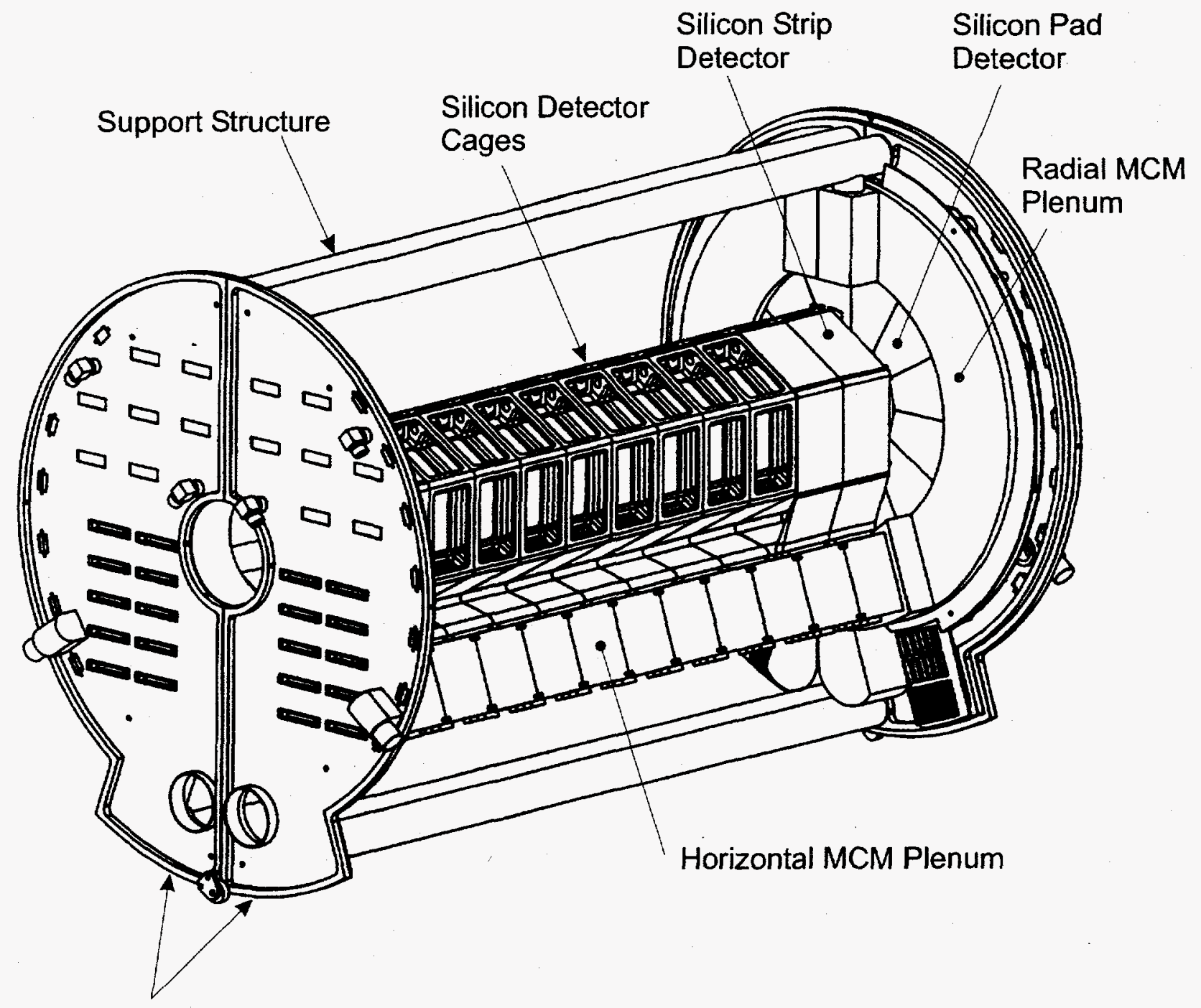

End Plates

Figure 1. Schematic diagram of the MVD showing the full set of silicon detector cage assemblies, horizontal MCM plenum, support structure, and end plates including motherboards, pad detectors, and radial MCM plenums. 
to show how the silicon strip detector locations on the Rohacell 'C-cages' could vary with humidity fluctuations. van Heck further showed how the vertex finding efficiency would decrease with excursions in humidity levels. For example, 5 and $10 \%$ reductions in the vertex finding efficiency were estimated to result from, respectively, relative humidity excursions of 9 and $18 \%$ at $23^{\circ} \mathrm{C}$. Using the $9 \%$ excursion of relative humidity as an acceptable limit and $30 \%$ relative humidity at $23^{\circ} \mathrm{C}$ as a mean base value, the authors specified an MVD enclosure relative humidity operating range of 21 to $39 \%$ at $23^{\circ} \mathrm{C}$ for this study. This relative humidity range corresponds to a specific humidity range of 0.0045 to $0.009 \mathrm{~kg} \mathrm{H}_{2} \mathrm{O} / \mathrm{kg}$ Air (at a LANL elevation).

In summary, the following performance goals were specified for the secondary air cooling system:

- Temperature range goal for enclosure: 10 to $20^{\circ} \mathrm{C}$

- Specific humidity range design goal:

(LANL conditions): 0.0045 to $0.009 \mathrm{~kg} \mathrm{H} \mathrm{H}_{2} \mathrm{O} / \mathrm{kg}$ Air (corresponding BNL conditions): 0.0035 to $0.007 \mathrm{~kg} \mathrm{H} \mathrm{H}_{2} \mathrm{O} / \mathrm{kg}$ Air

The purpose of this experiment was to determine the performance of the air cooling system in a realistic geometry, define assembly issues and limitations in the design, and to identify areas that need to be investigated further before finalizing the design. 


\section{EXPERIMENTAL METHODS}

For this experiment, a full-scale mockup of the PHENIX nose cones, to which the MVD mounts, and a mechanical prototype of one half of the MVD enclosure were used. The MVD outer and inner enclosure walls were fabricated from $6.35 \mathrm{~mm}(0.25$ in) thick Rohacell sheet and covered with an aluminum foil sheet that was fixed with dry adhesive (NT988-2 from Dielectric Polymers, Inc.). The aluminum foil serves primarily as an RF shield for the MVD instrumentation and secondarily as an insulator against moisture from the environment. The Rohacell enclosure walls were attached to the metal endplates of the MVD to form a complete enclosure, which was then was mounted to the nose cones.

A schematic of the experimental apparatus used in the present study is shown in Figure 2. Air flow was provided by two Ametek Windjammer blowers connected in parallel. Air was forced through a closed loop of $5.08 \mathrm{~cm}$ (2 in) PVC tubing that closely resembles the geometry of the anticipated final system. An air-to-water heat exchanger consisting of three Car Quest Transmission Oil Coolers connected to two water chillers (a VWR Scientific 1174 with $650 \mathrm{~W} @ 5^{\circ} \mathrm{C}$ and a Neslab Endocal RTE4 with $400 \mathrm{~W} @$ $0^{\circ} \mathrm{C}$ ) was used to cool the air and effectively remove waste heat from the system. Both of the chillers were quite old and it was observed that their cooling capabilities had been reduced as evident by their inability to reach their minimum coolant delivery temperatures. Consequently, the cooling capacities of the chillers were estimated to be reduced by at least $50 \%$ from the manufacturing specifications listed above. A dehumidifier, consisting of a $1 \mathrm{~m}$ long coil of $9.5 \mathrm{~mm}(0.375 \mathrm{in})$ diameter refrigeration tubing placed inside a steel housing, was used in conjunction with the heat exchangers to remove water vapor from the air flow loop. A Sper Scientific 840003 anemometer ( 0 to 


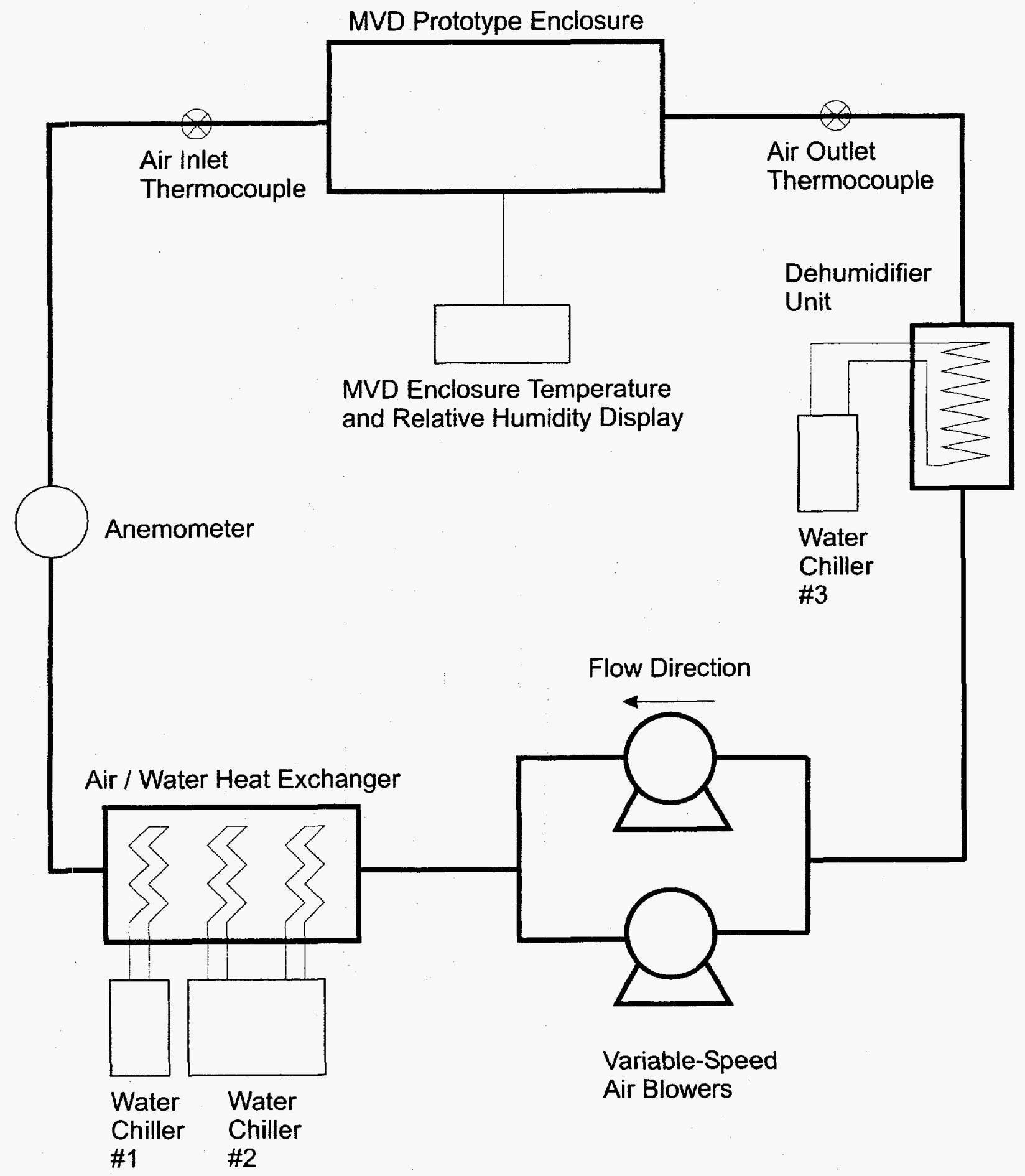

Figure 2. Schematic diagram of the experimental air cooling system for the MVD enclosure. 
$44.8 \mathrm{~m} / \mathrm{s}, 0.1 \mathrm{~m} / \mathrm{s}$ resolution with $+/-3 \%$ accuracy) was used to monitor the inlet air flow rate. Type $\mathrm{T}$ thermocouples, with an accuracy of $\pm 0.5^{\circ} \mathrm{C}$, were used to record the temperatures of the MVD inlet and outlet air at the respective MVD air line connectors. An Omega HX11V temperature compensated relative humidity probe was used to monitor the moisture level within the MVD enclosure.

Air entered and exited the MVD through $5.08 \mathrm{~cm}(2$ in) diameter access holes and flowed through the entire MVD enclosure without restriction. The $5.08 \mathrm{~cm}(2 \mathrm{in})$ diameter access holes were chosen over the $1.91 \mathrm{~cm}(0.75 \mathrm{in})$ versions detailed in the current MVD design because the air blowers used in the present study could not overcome the pressure drop induced by the latter hole diameter fittings and tubing.

A second means to control humidity within the enclosure was attempted with a nitrogen gas cylinder connected to the flow loop $65 \mathrm{~cm}$ (25.6 in) downstream of the heat exchanger, injecting nitrogen at a constant rate of approximately $7450 \mathrm{cc} / \mathrm{min}$. Flow of the nitrogen gas was measured using a Gilmont $15-\mathrm{cm}$ flow meter. A one-way valve located $15 \mathrm{~cm}(5.9 \mathrm{in})$ upstream of the nitrogen inlet was used to bleed air from the loop while nitrogen was being injected.

The experiments were begun with cooling the circulating air by using the water chillers to bring the air temperature to the desired value. After steady-state operation was achieved, measurements were taken of the inlet and outlet air temperatures, the relative humidity inside and outside the MVD, and the temperature of the environment. During the first series of humidity control tests, the nitrogen was turned on and the one-way valve opened to bleed air out of the system; some adjustment of the water chillers was needed at this time, since the nitrogen tended to warm the inlet air by about $2^{\circ} \mathrm{C}$. When steady 
state was reached, measurements were taken again of all the values indicated earlier, and several experiments were conducted under identical operating conditions to ensure reproducibility. Experiments were run both with and without injected nitrogen for air inlet temperatures of 10,15 , and $20^{\circ} \mathrm{C}$, and at air flow rates of $0.005,0.010$, and 0.015 $\mathrm{m}^{3 / \mathrm{s}}$. For the second series of humidity control tests, the dehumidifier unit was employed. This simply required turning on the water chiller connected to the dehumidifier and allowing it to reach the desired coolant supply operating temperature. Again, measurements were made upon reaching steady-state conditions. It should be noted that the air pressure at Los Alamos National Laboratory (LANL), where this experiment was conducted, is approximately $80.3 \mathrm{KPa}(11.5 \mathrm{psi})$, which is less than the air pressure of 101.3 $\mathrm{KPa}(14.5 \mathrm{psi})$ at Brookhaven National Laboratory (BNL) where the MVD will be installed and operated. Consequently, all specific humidity measurements given in this report refer to the values measured at LANL. To determine the corresponding specific humidity value for BNL, $\gamma_{B N L}$. (that represents a moisture mass content equal to that at LANL for a given volume of air), the specific humidity value reported for LANL, $\gamma_{L A N L}$. must be multiplied by the atmospheric pressure ratio, $\left(P_{L A N L} / P_{B N I}\right)$, or

$$
\gamma_{B N L}=0.79 \gamma_{L A N L}
$$

\section{EXPERIMENTAL RESULTS}

The experimental results are broken down into two separate sections. The first section discusses the temperature control of the MVD enclosure with an emphasis on the 
thermal performance of the associated hardware components, the latter of which is needed for the final cooling system design. The second section presents the experimental results of the three different techniques used to control the humidity level within the MVD enclosure.

\section{Temperature Control}

The results presented in this section show the effects of air flow rate and air inlet temperature on the internal temperatures of the MVD and on the heat load imposed on the MVD enclosure by the environment. Figure 3 displays the average internal temperature of the MVD enclosure as a function of volumetric air flow rate and inlet air temperature. The data shows a fairly linear dependence of the enclosure temperature on the inlet air temperature. It also indicates that while the prototype system could maintain the enclosure temperature below $20^{\circ} \mathrm{C}$, it had difficulty reaching the desired lower limit of $10^{\circ} \mathrm{C}$ for all flow rates. This limitation was due to an inadequate cooling capacity of the liquid chillers used in the present investigation. Extrapolation of the data suggests that the lower limit of $10^{\circ} \mathrm{C}$ could be obtained with an inlet air temperature of $8^{\circ} \mathrm{C}$ at a flow rate of $0.015 \mathrm{~m}^{3} / \mathrm{s}$. This would require a slightly larger capacity water chiller than the one used in the current prototype.

Figure 4 presents the heat load imposed by the environment on the MVD enclosure versus air inlet temperature for various air flow rates. The enclosure heat load was calculated from the air inlet and outlet temperatures, $T_{i}$ and $T_{0}$, and the air volumetric flow rate, $Q$, using the following energy balance on the MVD enclosure:

$$
q_{m v d}=\rho Q c_{p}\left(T_{o}-T_{i}\right)
$$




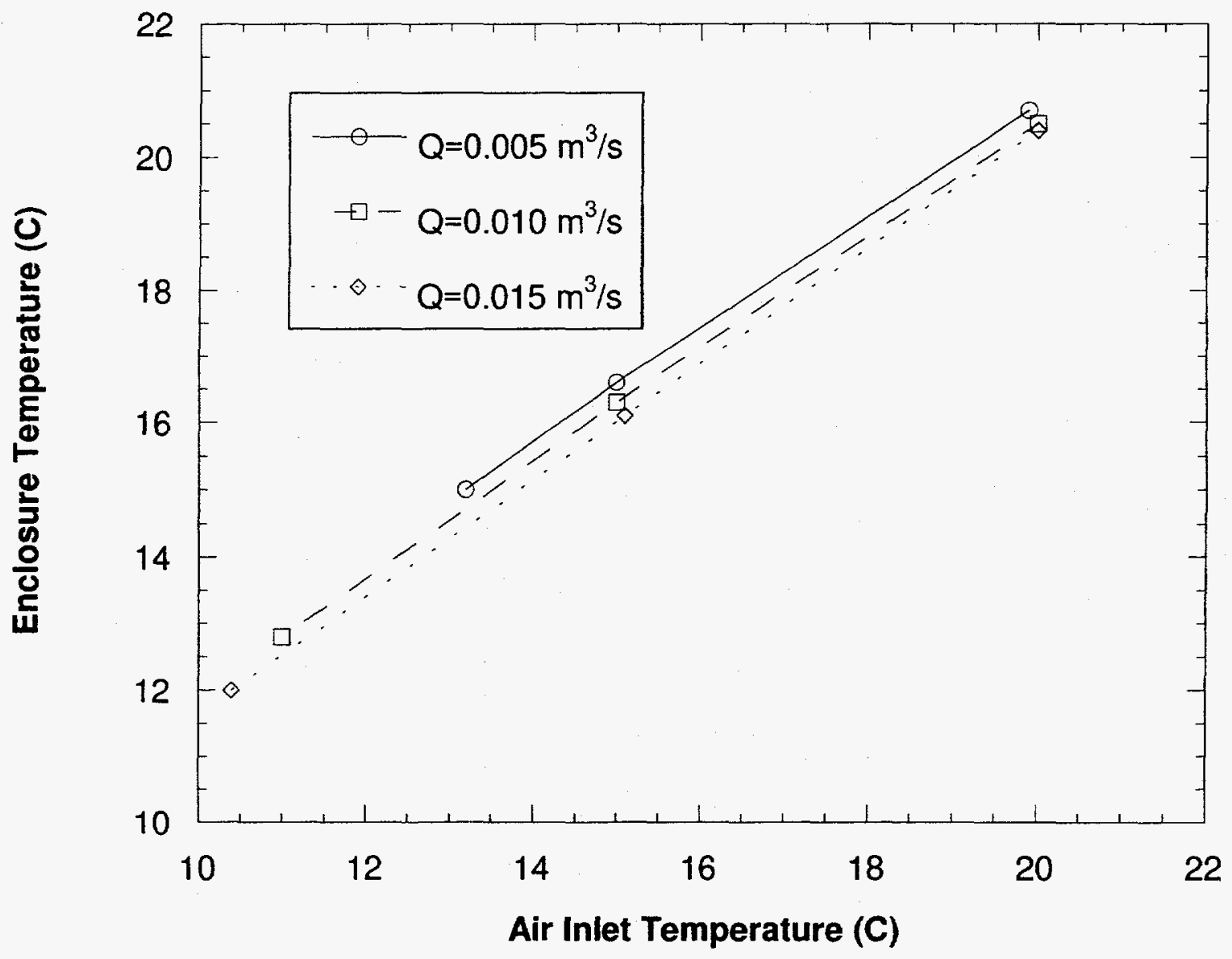

Figure 3. MVD enclosure temperature as a function of air inlet temperature for various air volumetric flow rates. 


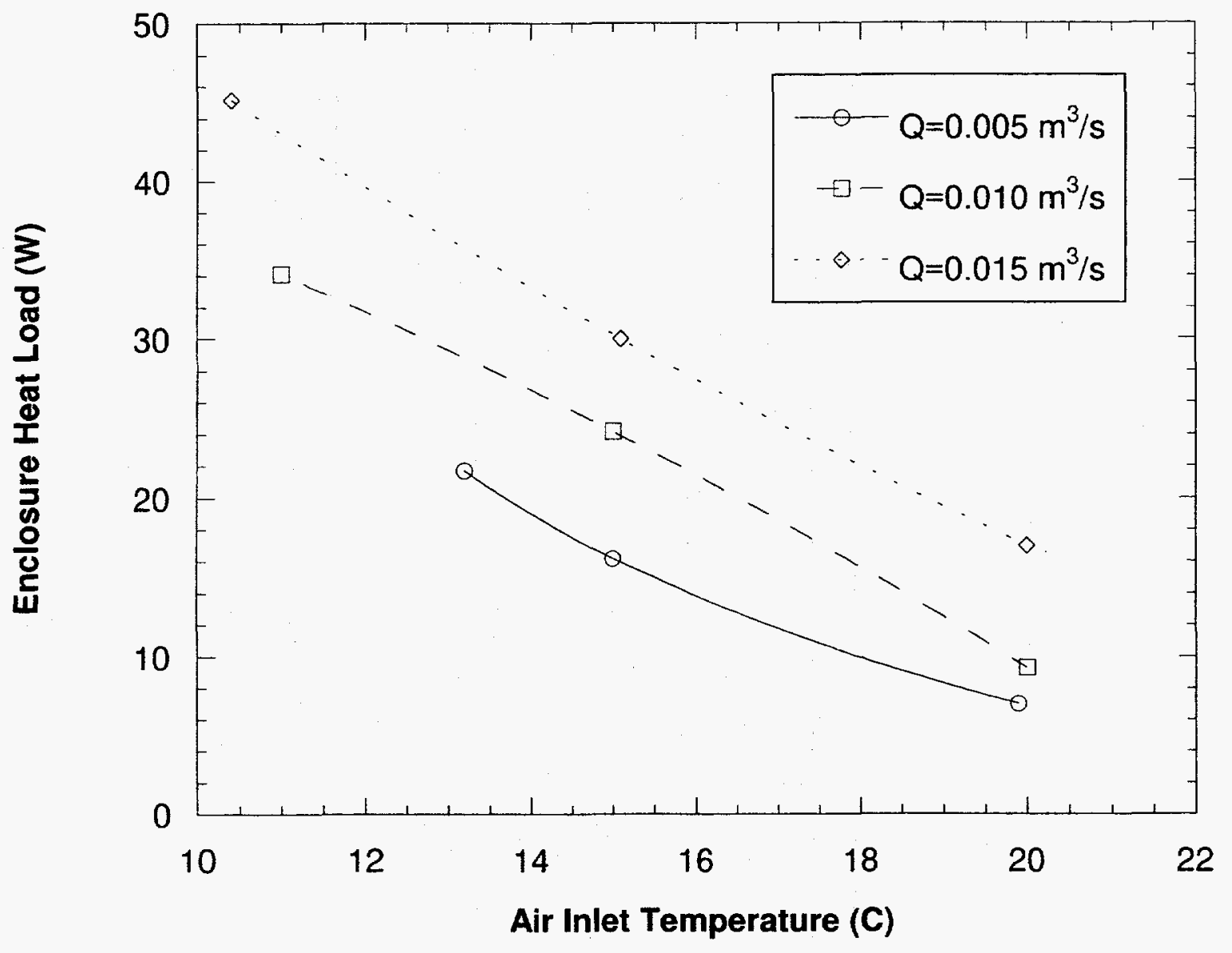

Figure 4. MVD enclosure heat load as a function of air inlet temperature for various air volumetric flow rates. 
As the data of Figure 4 verifies, the heat loads increase with decreasing inlet air temperature and with increasing air flow rates.

The data of Figure 4 only presents the heat load imposed on the secondary air cooling system by the MVD. Calculations from a previous study [2], which used the same cooling loop hardware, suggest a heat load on the order of $200 \mathrm{~W}$ would be provided by the air blowers, tubing, and adapters. Consequently, the final cooling system design must be capable of removing at least $300 \mathrm{~W}$ of waste heat.

\section{Humidity Control}

The results presented in this section show the effects of various forms of humidity control on the specific humidity inside the MVD enclosure. There are no results shown for an attempted use of Drierite desiccant (Fischer Scientific) as humidity control, since its use proved completely ineffective due to the high pressure drop imposed upon the blowers by the desiccant chamber. Smaller amounts of the desiccant with a manageable pressure drop proved ineffective in drying the air to any significant degree.

Figure 5 shows the effects of adding dry nitrogen gas into the flow loop while simultaneously bleeding off air from the flow loop upstream of the nitrogen inlet. It was expected that this addition of dry gas into the loop would dehumidify the air but the effects were minimal, and in several cases, immeasurable. It is speculated that the drying effect of the nitrogen gas was overshadowed by continual seepage of moist laboratory air into the flow loop through air leaks in the MVD prototype and tubing joints. These small, yet observable leaks were due in part to inadequate machining tolerances on the air flow adapters and the Rohacell shell forming the outer enclosure. 


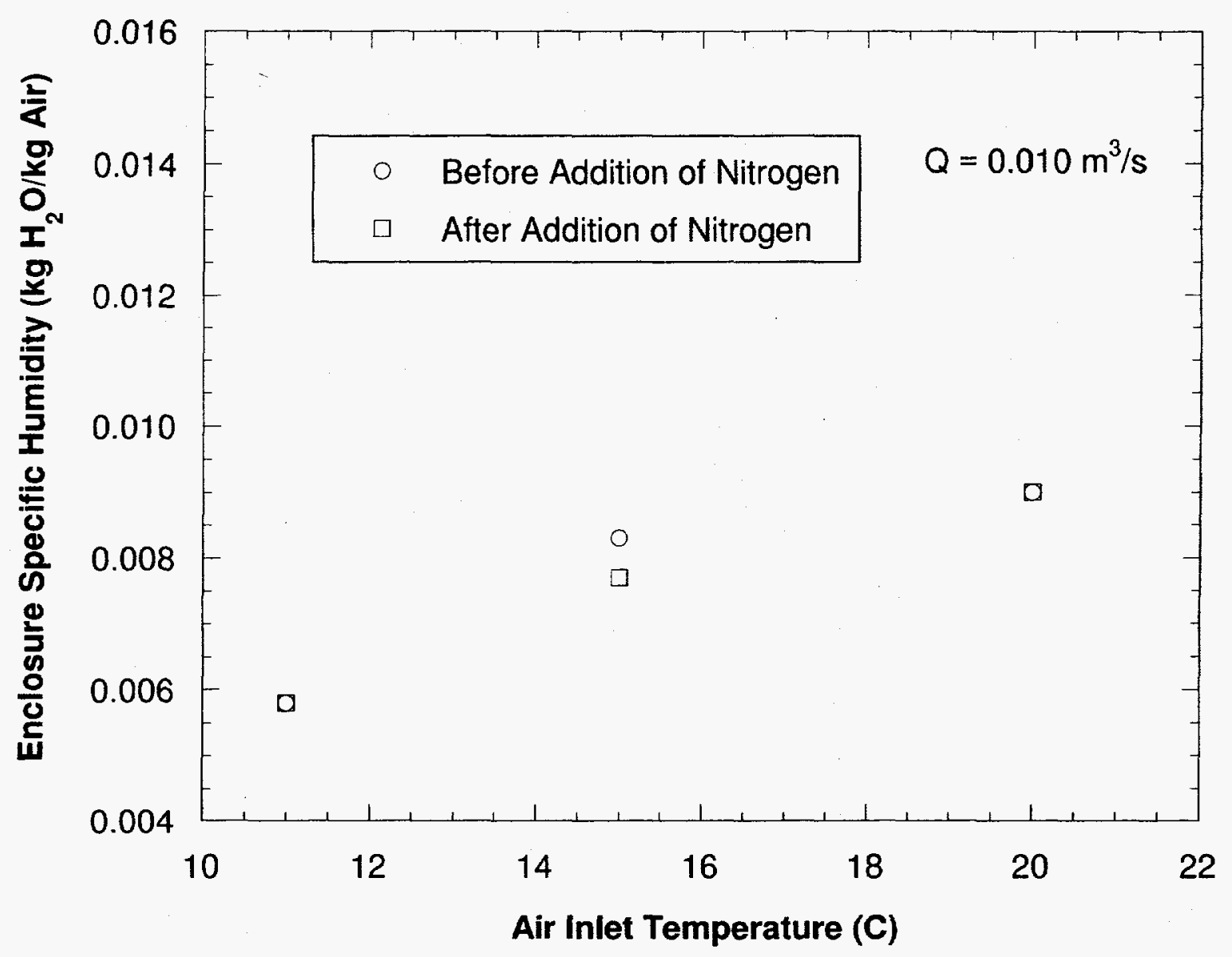

Figure 5. MVD enclosure specific humidity as a function of air inlet temperature with and without the addition of dry nitrogen for an air volumetric flow rate of $0.010 \mathrm{~m}^{3} / \mathrm{s}$. 
Figure 6 shows the effects of dehumidification of the enclosure air by condensing water vapor on the air-to-water heat exchanger. The two cases represented in Figures 6(a) and 6(b) correspond respectively, to enclosure prototypes without and with an aluminum foil layer affixed to the outer surface of the enclosure rohacell. This was attempted to assess the effectiveness of using the foil as a moisture leak inhibitor in addition to its primary purpose as an RF shield. In both tests, the dehumidifier unit was shut off to isolate the dehumidifying performance of the air-to-water heat exchanger. Plotted in Figure $6(a)$ and $6(b)$ are the specific humidity within the enclosure for various air flow rates and air inlet temperatures. The laboratory specific humidity, or that in the flow loop prior to each experiment, ranged between 0.0085 and $0.0105 \mathrm{~kg} \mathrm{H}_{2} 0 / \mathrm{kg}$ Air. The trend in the data is for the specific humidity to decrease with decreasing inlet air temperature and decreasing air flow rates. This agrees with thermodynamic principles and intuition. As the heat exchanger was run at a lower temperature to achieve cooler air temperatures, the potential for increased condensation on the sub dew-point temperature surfaces was enhanced. In addition, as the air flow rate was reduced, more time became available for condensation of the water vapor on the heat exchanger surfaces as the air passed over them.

Figure 7 displays the limited effectiveness of the dehumidifier unit on removing moisture from the flow loop with a liquid (water/antifreeze mixture) inlet temperature of $0^{\circ} \mathrm{C}$. In the test used to generate the specific humidity data of Figure 7 , the water chiller connected to the air-to-water heat exchanger was shut off so only the dehumidifier unit would have the potential to condense moisture from the circulating air. As the data indicates, the dehumidifier decreases the specific humidity level by only $0.001 \mathrm{~kg} \mathrm{H}_{2} \mathrm{O} / \mathrm{kg}$ Air during a transient period of 45 minutes. As in the earlier tests, it is believed that air 


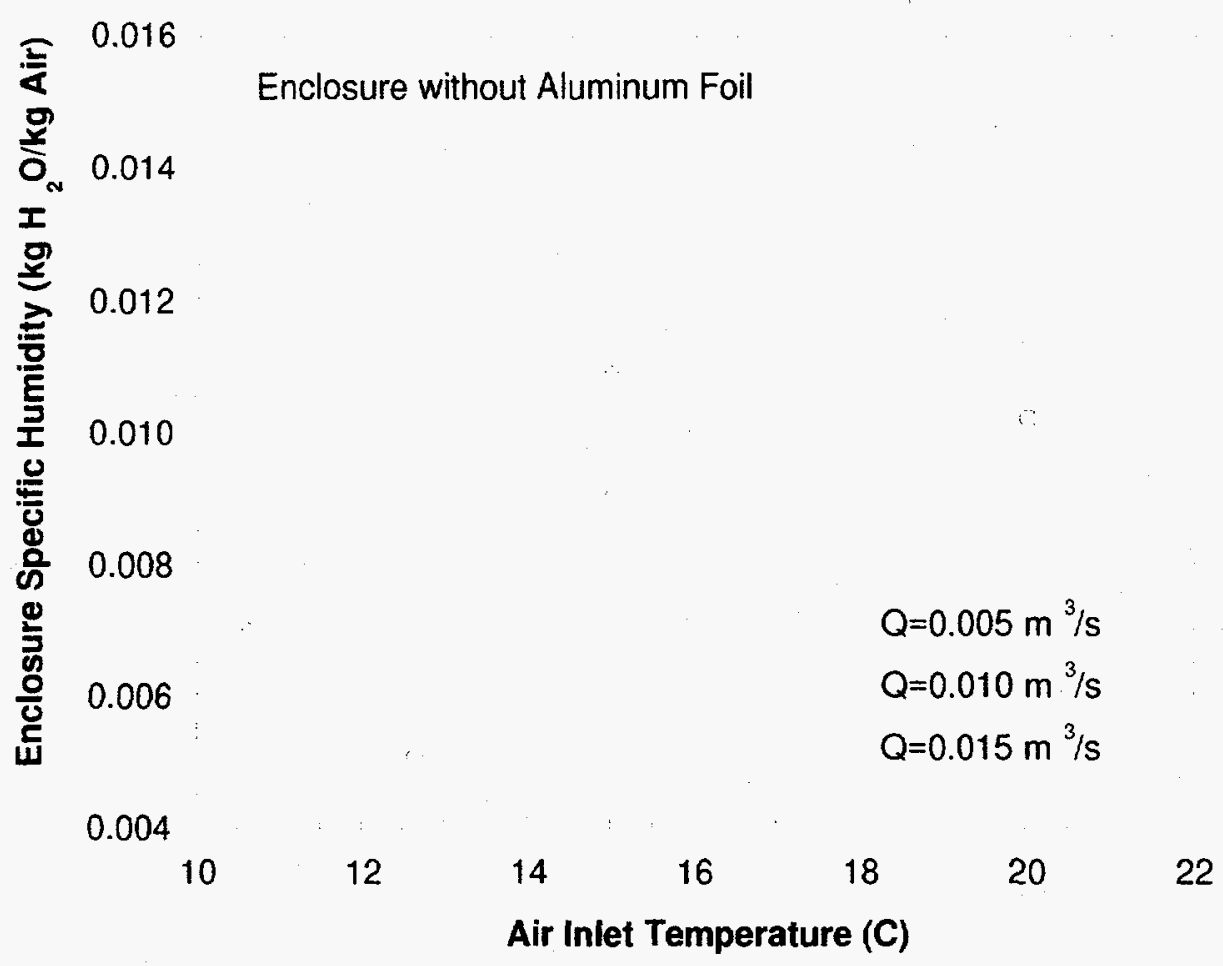

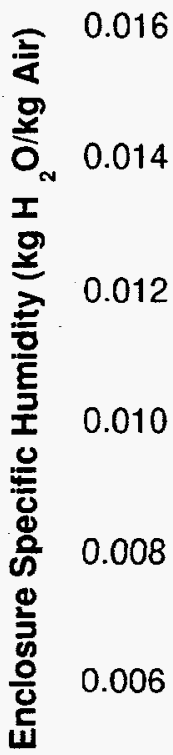

(a)

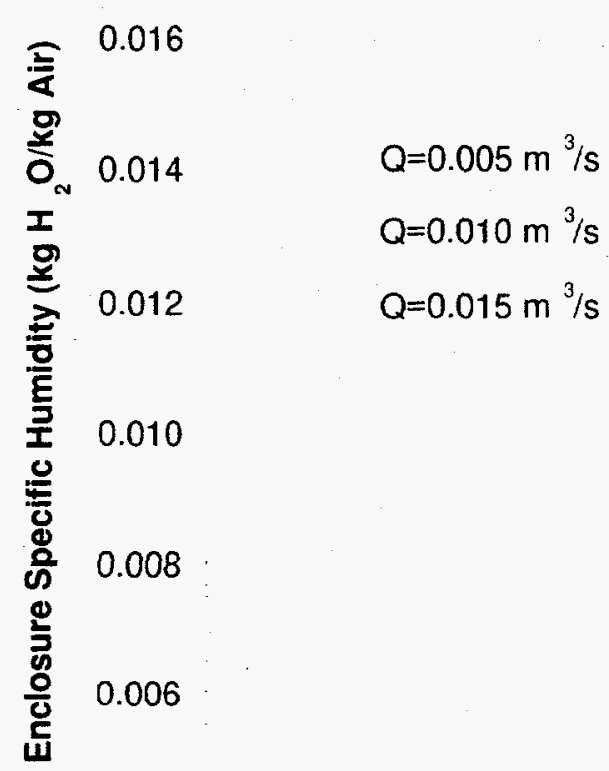

0.004

10

12

14

16

18

20

22

\section{Air Inlet Temperature (C)}

(b)

Figure 6. MVD enclosure specific humidity as a function of air inlet temperature for various air inlet temperatures and an enclosure prototype shell

(a) without and (b) with aluminum foil. 


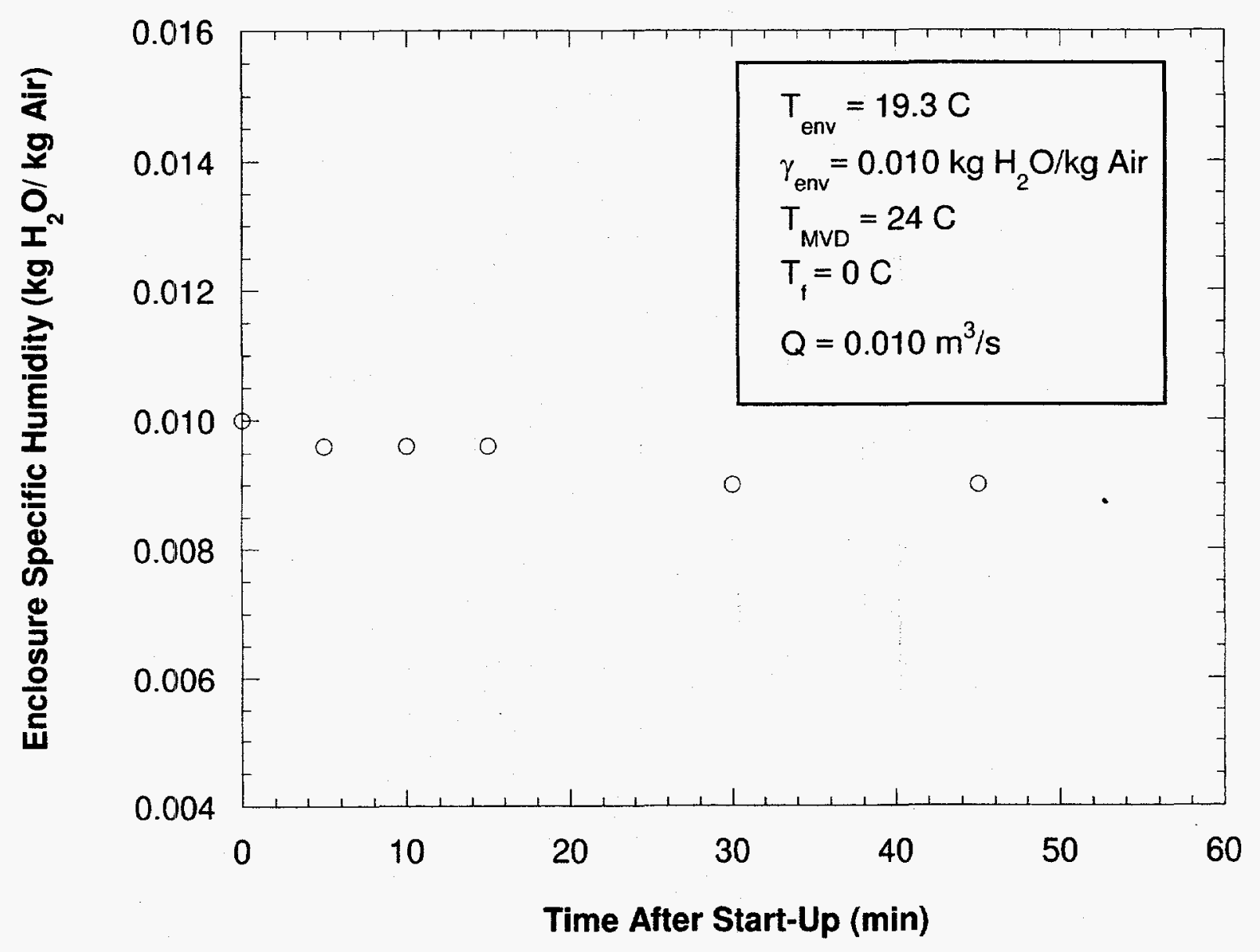

Figure 7. MVD enclosure specific humidity as a function of time using only the dehumidifier unit for moisture removal. 
leaks in the flow loop acted as a continuous source of moisture and thus prevented the dehumidifier from reducing the specific humidity to lower levels.

The test used to generate the specific humidity data of Figure 7, was repeated with a lower dehumidifier liquid inlet temperature of $-5^{\circ} \mathrm{C}$. As Figure 8 displays, the lower liquid temperature allowed the dehumidifier unit to reduce the specific humidity in the enclosure by $0.0025 \mathrm{~kg} \mathrm{H}_{2} \mathrm{O} / \mathrm{kg}$ Air, more than twice the reduction obtained with the $0^{\circ} \mathrm{C}$ inlet liquid supply temperature. Figure 8 also shows how turning on the the air-to-water heat exchanger (with a liquid supply temperature of $1^{\circ} \mathrm{C}$ ), after reaching steady state with the dehumidifier unit, reduced the enclosure's specific humidity by another $0.0023 \mathrm{~kg}$ $\mathrm{H}_{2} \mathrm{O} / \mathrm{kg}$ Air. Thus as expected, the specific humidity of the enclosure can be reduced by either reducing the liquid supply temperature below the dew point temperature, or by increasing the surface area available for condensation. 


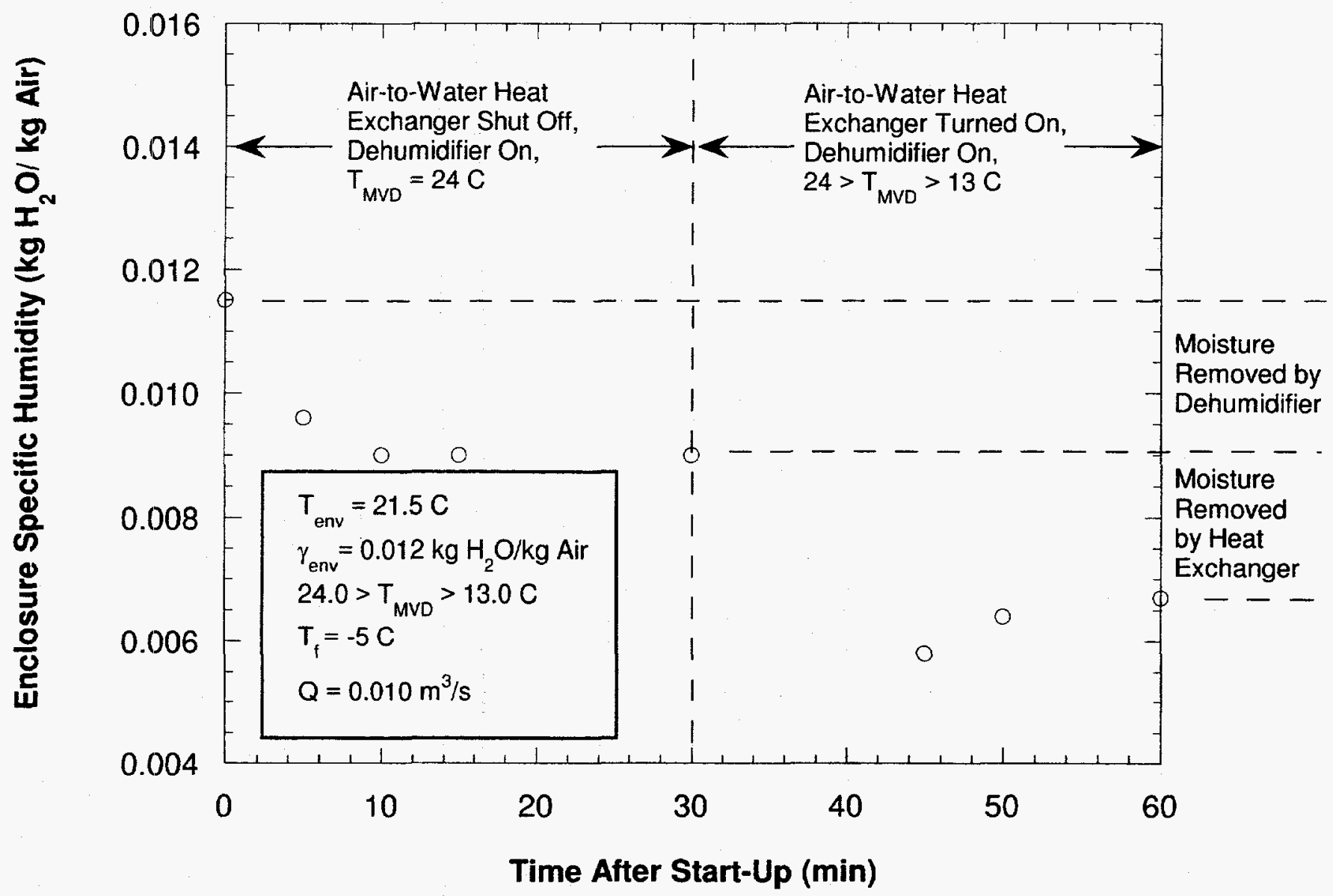

Figure 8. MVD enclosure specific humidity as a function of time using the dehumidifier unit by itself and with the air-to-water heat exchanger for moisture removal. 


\section{CONCLUSIONS AND DESIGN RECOMMENDATIONS}

These experiments investigated the performance of a prototype air cooling system in removing waste heat and in controlling the humidity of the MVD enclosure. From the results of this study, the following key conclusions can be drawn:

1. While the prototype system was successful in maintaining the enclosure temperature below the upper design limit of $20^{\circ} \mathrm{C}$, it could not reach the desired lower limit of $10^{\circ} \mathrm{C}$. A larger capacity water chiller would be needed to supply an inlet air temperature at or below $8^{\circ} \mathrm{C}$ to obtain the $10^{\circ} \mathrm{C}$ operating temperature of the MVD enclosure with the air flow rates used in this study.

2. The specific humidity of the MVD's enclosure was found to be insensitive to the presence of a desiccant or the injection of dry nitrogen into the coolant air flow. It is speculated that air leaks in the MVD prototype and air flow loop acted as a constant source of moisture from the laboratory environment which overshadowed the dehumidifying effects of these methods.

3. Condensation on the air-to-water heat exchanger surfaces was the most effective means of removing water vapor from the cooling system air. The specific humidity in the MVD's enclosure was found to decrease by decreasing the heat exchanger coolant supply temperature and the air flow rate.

4. To prevent excess condensation build-up on the heat exchanger surfaces, a dehumidifier unit consisting of a coil of copper tubing containing a coolant was added to the air flow loop. This unit, when run with a liquid supply temperature of $-5^{\circ} \mathrm{C}$, was able to remove an equal amount of moisture as the air-to-water heat exchanger 
while supplying an MVD air inlet temperature of $13^{\circ} \mathrm{C}$. Consequently, this dehumidifier could be designed and used to effectively remove moisture from the air cooling loop and prevent condensation build-up in the heat exchanger.

The results of this study indicate that the prototype cooling and dehumidification system for the MVD enclosure can meet the operating criteria with a few modifications. In particular, the final design should give careful attention to the following key issues:

1. The $19.1 \mathrm{~mm}(0.75 \mathrm{in})$ diameter air inlet and outlet adapters for the MVD secondary air cooling flow loop provided too large of a pressure drop for the air blowers to accommodate. In the present study, $50.8 \mathrm{~mm}$ (2.0 in) adapters were used effectively with a manageable pressure drop. Consequently, either the inlet and outlet air ports for the secondary air cooling system must be enlarged or larger capacity air blowers must be utilized.

2. Careful attention must be given to ensure the leak-tight integrity of the final MVD enclosure and secondary air cooling flow loop. Proper fittings and sealants should be employed to eliminate potential sources of moisture from the outer environment.

3. A larger capacity water chiller (on the order of $600 \mathrm{~W} @ 0^{\circ} \mathrm{C}$ ) is needed for the air-towater heat exchanger in order to meet the lower MVD enclosure operating temperature of $10^{\circ} \mathrm{C}$. The chillers used in the present study were quite old and it is uncertain as to their current cooling capacity.

4. A robust dehumidifier unit, similar to the one used in this study, must be designed for the final MVD assembly. In particular, a chiller with a liquid supply temperature of - 
$20^{\circ} \mathrm{C}$ is desirable for this unit. In addition, the dehumidifier should possess a means of removing moisture from its casing. For example, excess liquid build-up from condensation could be removed with either a valve or wicking mechanism.

5. If the MVD enclosure and cooling system is properly sealed from the environment, then a reliable method for maintaining a desired humidity level within the enclosure must be developed. This could be achieved by using a humidity probe and controller to manipulate the power input to the dehumidifier unit's chiller, and hence control the moisture removal process. This would be quite effective if the desired humidity level is sufficiently low as to prevent the need for adding significant amounts of moisture to the air flow loop.

\section{References}

[1] Multiplicity and Vertex Detector Web Site: http://p2hp2.lanl.gov/phenix/mvd.

[2] J.D. Bernardin, E. Bosze, D. Clark, J. Boissevain, and J. Simon-Gillo, 1997, "An Experimental Investigation of an Air Cooling Scheme for the Multichip Modules of the Multiplicity and Vertex Detector," Technical Note LA-13320-MS, Los Alamos National Laboratory, Los Alamos, NM 87545.

[3] E. Bosze, J. Simon-Gillo, J. Boissevain, J. Chang, R. Seto, "Rohacell Foam as a Silicon Support Structure Material for the PHENIX Multiplicity Vertex Detector," Nuclear Instruments and Methods (in Press).

[4] van Heck, H., 1997, "MVD Mechanical Tolerance Studies," PHENIX Technical Note, PHENIX-MVD-97-24, PHENIX Note \#307, Los Alamos National Laboratory, Los Alamos, NM, 87545. 